2012-04

Noninvasive prenatal testing for aneuploidyready for prime time?

Wright, DE

http://hdl.handle.net/10026.1/1209

10.1016/j.ajog.2012.02.021

American Journal of Obstetrics \& Gynecology

All content in PEARL is protected by copyright law. Author manuscripts are made available in accordance with publisher policies. Please cite only the published version using the details provided on the item record or document. In the absence of an open licence (e.g. Creative Commons), permissions for further reuse of content should be sought from the publisher or author. 


\title{
Noninvasive prenatal testing for aneuploidy-ready for prime time?
}

\author{
Lyn S. Chitty, MRCOG; Melissa Hill, PhD; Helen White, PhD; David Wright, PhD; Stephen Morris, PhD
}

$\mathrm{N}_{\mathrm{i}}$ oninvasive prenatal diagnosis using cell-free fetal DNA in the maternal plasma is moving into routine clinical practice for some indications. Here we discuss exciting developments in noninvasive prenatal diagnosis for aneuploidy afforded by recent publications, including 2 papers published in this journal, and highlight some of the issues that need to be considered before these tests can be implemented as part of routine antenatal care.

Finally, after years of hunting for the elusive fetal cells in the maternal circulation to use for genetic prenatal diagnosis, ${ }^{1}$ it seems that cell-free fetal DNA (cffDNA) will provide the basis for a safer, noninvasive approach to prenatal diagnosis. Since the identification of cffDNA in maternal plasma in the late 1990s, ${ }^{2}$ there has been much research on how cffDNA can be used as an alternative to invasive tests to provide safer, yet robust, noninvasive prenatal diagnosis (NIPD) for families at high risk of genetic disorders and for other pregnancy complications such as hemolytic disease of the newborn and fetal aneuploidy. In recent months we have seen the publication of papers describing implementation of this technology into routine obstetric practice to direct administration of anti-D for all $\mathrm{RhD}$-negative mothers ${ }^{3}$ and as part of standard genetic care to determine fetal sex for women at high risk of sex-linked disorders. The clinical utility of NIPD in reducing the need for invasive testing ${ }^{4-6}$ and favorable costs have been clearly demonstrated. ${ }^{7}$

There have been a variety of approaches to the noninvasive diagnosis of aneuploidy reported (Table 1), culminating in the

From the Clinical and Molecular Genetics Unit, University College London Institute of Child Health (Drs Chitty and Hill), Great Ormond Street Hospital for Children National Health Service Trust (Dr Hill), and Center of Applied Health Research, Research Department of Epidemiology and Public Health, University College London (Dr Morris), London; National Genetics Reference Laboratory (Wessex), Salisbury District Hospital, Salisbury (Dr White); and School of Computing and Mathematics, University of Plymouth, Plymouth (Dr Wright), United Kingdom.

L.S.C., M.H., H.W., and S.M. are part of the RAPID Team, which is funded by the National Institute for Health Research (NIHR) Program Grants for Applied Research (RP-PG-0707-10107). L.S.C. and S.M. are partially funded by the NIHR Biomedical Research Center at University College National Health Service Foundation Trust and University College London. L.S.C. receives support from the Great Ormond Street Hospital Children's Charity. The views expressed in this article are those of the authors and not necessarily those of the National Health Service, the $\mathrm{NIHR}$, or the Department of Health.

Reprints not available from the authors.

0002-9378/free

(C) 2012 Published by Mosby, Inc.

doi: 10.1016/j.ajog.2012.02.021

See related articles, pages 319 and 322 recent publication of several validation projects demonstrating good sensitivities and specificities for the detection of trisomy 21 using next-generation sequencing. ${ }^{8,9}$ Such is the volume of work generated over recent years that we are now seeing the publication of systematic reviews describing the application of NIPD for both fetal sex determination ${ }^{10}$ and aneuploidy diagnosis. ${ }^{11}$ In this issue, we see 2 papers published describing an alternative sequencing approach to NIPD for aneuploidy that employs targeted, or chromosome-selective, sequencing that appears to be highly accurate and potentially more cost-effective than previously reported sequencing approaches.

Given that technological advances are bringing noninvasive testing for aneuploidy ever closer, here we aim to initiate discussions on how implementation might proceed. In the course of developing the arguments we have made several assumptions, which may or may not be born out in practice when larger studies are published. Specifically, will/should it be noninvasive prenatal diagnosis or should it be an extension of noninvasive prenatal screening; ${ }^{12}$ will this new service be delivered universally across the developed world; how will current practices influence service delivery; what are the cost implications, what do consumers think, and how should we incorporate their views; and finally, will it be necessary or possible to regulate the provision of NIPD by commercial companies?

The 2 papers published in this issue describe the use of massively parallel sequencing for NIPD of trisomies 18 and 21 using assays targeted to nonpolymorphic loci on chromosomes 18 and 21. The first stage of this work, reported elsewhere, ${ }^{13}$ described the development of a multiplex assay, termed "digital analysis of selected regions," comprising targets on chromosomes 18 and 21. In the first of the papers reported in this journal, digital analysis of selected regions is used to develop an algorithm, fetal-fraction optimized risk of trisomy (FORTE), which uses the proportion of specific cffDNA in the samples, estimated by targeting additional sequences not usually involved in aneuploidy, and the prior risk of trisomy (taken from published data on maternal and fetal gestational age related risks) to estimate the risk of trisomies 18 and $21 .{ }^{14}$ The authors then describe its application in 2 cohorts; the first cohort was used to develop quality-control parameters, and the second to evaluate performance in a blinded, small group of samples. In the second study by Ashoor et al, ${ }^{15} 400$ samples from pregnancies with known karyotypes, 300 from euploid pregnancies and 50 each from pregnancies affected by trisomy 18 and 21, were analyzed by Sparks' laboratory to give an estimate of risk for trisomy 18 and 21. Both papers report high degrees of accuracy, with the second paper reporting correct identification of all trisomy 21 fetuses, $98 \%$ of those with trisomy 18 having all euploid fetuses correctly identified, and a very low (1\%) assay 
TABLE 1

\section{Summary of studies reporting detection of fetal aneuploidy using variety of methods of noninvasive prenatal diagnosis}

\begin{tabular}{|c|c|c|c|c|c|c|}
\hline Study & Method & $\begin{array}{l}\text { Total no. } \\
\text { samples } \\
\text { tested }\end{array}$ & $\begin{array}{l}\text { No. normal samples } \\
\text { tested (true } \\
\text { negatives) }\end{array}$ & $\begin{array}{l}\text { No. aneuploid } \\
\text { samples } \\
\text { tested (true } \\
\text { positive) }\end{array}$ & $\begin{array}{l}\text { Sensitivity, \% } \\
(95 \% \text { Cl) }\end{array}$ & $\begin{array}{l}\text { Specificity, \% } \\
\left(^{(95 \% ~ C l)^{a}}\right.\end{array}$ \\
\hline Lo et $\mathrm{al}^{16}$ & RNA allelic ratio & 67 & $57(55)$ & $10(9)$ & $90(60.6-99.5)$ & $96.5(89.4-99.4)$ \\
\hline Tsui et al ${ }^{17}$ & RNA allelic ratio & 62 & $58(51)$ & $4(4)$ & $100(47.3-100)$ & $89.7(80.6-95.4)$ \\
\hline Fan et al ${ }^{18,19}$ & MPS & 18 & $\begin{array}{l}\text { T21 cohort: } 9 \text { (9) } \\
\text { T18 cohort: } 16 \text { (16) } \\
\text { T13 cohort: } 17(17)\end{array}$ & $\begin{array}{l}\text { T21: } 9(9) \\
\text { T18: } 2(2) \\
\text { T13: } 1(1)\end{array}$ & $\begin{array}{l}\text { T21: } 100(71.8-100) \\
\text { T18: } 100(22.4-100) \\
\text { T13: } 100(5-100)\end{array}$ & $\begin{array}{l}\text { T21: } 100(71.8-100) \\
\text { T18: } 100(82.9-100) \\
\text { T13: } 100(83.8-100)\end{array}$ \\
\hline Chiu et $\mathrm{al}^{20}$ & MPS & 28 & $14(14)$ & $14(14)$ & $100(80.7-100)$ & $100(80.7-100)$ \\
\hline Ghanta et $\mathrm{al}^{21}$ & Tandem SNP & 27 & $20(20)$ & $7(7)$ & $100(65.2-100)$ & $100(86.1-100)$ \\
\hline Tong et $\mathrm{al}^{22}$ & Differential methylation & 29 & $24(23)$ & $5(5)$ & $100(55-100)$ & 95.8 (81.7-99.8) \\
\hline Papageorgiou et $\mathrm{al}^{23}$ & Differential methylation & 40 & $26(26)$ & $14(14)$ & $100(80.7-100)$ & $100(89.2-100)$ \\
\hline Deng et $\mathrm{al}^{24}$ & RT-MLPA & 113 & $87(87)$ & $25(23)$ & 92 (77-98.6) & $100(96.6-100)$ \\
\hline Chiu et $\mathrm{a}^{25}$ & MPS & 15 & $10(10)$ & $5(5)$ & $100(54.9-100)$ & $100(74.2-100)$ \\
\hline Sehnert et $\mathrm{al}^{26}$ & MPS & 47 & $\begin{array}{l}\text { T21 cohort: } 34 \text { (34) } \\
\text { T18 cohort: } 39 \text { (39) } \\
\text { T13 cohort: } 46 \text { (46) }\end{array}$ & $\begin{array}{l}\text { T21: } 13 \text { (13) } \\
\text { T18: } 8 \text { (8) } \\
\text { T13: } 1 \text { (no call) }\end{array}$ & $\begin{array}{l}\text { T21: } 100(79.5-100) \\
\text { T18: } 100(68.8-100) \\
\text { T13: - }\end{array}$ & $\begin{array}{l}\text { T21: } 100(91.6-100) \\
\text { T18: } 100(92.6-100) \\
\text { T13: } 100(93.7-100)\end{array}$ \\
\hline Chen et $\mathrm{al}^{27}$ & MPS (2 plex) & 289 & $\begin{array}{l}\text { T13 cohort: } 264(261) \\
\text { T18 cohort: } 252 \text { (248) }\end{array}$ & $\begin{array}{l}\text { T18: } 37 \text { (34) } \\
\text { T13: } 25 \text { (25) }\end{array}$ & $\begin{array}{l}\text { T18: } 91.9 \text { (80.4-97.8) } \\
\text { T13: } 100 \text { (88.8-100) }\end{array}$ & $\begin{array}{l}\text { T18: } 98.9 \text { (97.1-99.7) } \\
\text { T13: } 98.4 \text { (96.4-99.4) }\end{array}$ \\
\hline Ehrich et al ${ }^{28}$ & MPS (4 plex) & 449 & $410(409)$ & $39(39)$ & $100(92-100)$ & $99.7(98.8-99.9)$ \\
\hline Lau et al ${ }^{29}$ & MPS (12 plex) & 108 & $\begin{array}{l}\text { T21 cohort: } 97 \text { (97) } \\
\text { T18 cohort: } 98 \text { (98) } \\
\text { T13 cohort: } 106(106)\end{array}$ & $\begin{array}{l}\text { T21: } 11(11) \\
\text { T18: } 10(10) \\
\text { T13: } 2(2)\end{array}$ & $\begin{array}{l}\text { T21: } 100(76.2-100) \\
\text { T18: } 100(74.5-100) \\
\text { T13: } 100(22.4-100)\end{array}$ & $\begin{array}{l}\text { T21: } 100(97-100) \\
\text { T18: } 100(97-100) \\
\text { T13: } 100(97.2-100)\end{array}$ \\
\hline Chiu et $\mathrm{al}^{8}$ & MPS (8 plex) & 657 & $571(6)$ & $86(68)$ & 79.1 (70.6-86) & 98.9 (97.9-99.5) \\
\hline Chiu et $\mathrm{al}^{8}$ & MPS (2 plex) & 232 & $146(3)$ & $86(86)$ & $100(96.6-100)$ & $97.9(94.8-99.8)$ \\
\hline Palomaki et al ${ }^{9}$ & MPS & 1683 & 1471 (1468) & 212 (209) & 98.6 (96.4-99.6) & 99.8 (99.5-99.9) \\
\hline Sparks et $\mathrm{al}^{14}$ & Targeted MPS & 167 & $123(123)$ & $\begin{array}{l}\text { T21: } 36(36) \\
\text { T18: } 8(8)\end{array}$ & $\begin{array}{l}\text { T21: } 100(92.1-100) \\
\text { T18: } 100(68.8-100)\end{array}$ & $\begin{array}{l}\text { T21: } 100(97.6-100) \\
\text { T18: } 100(97.6-100)\end{array}$ \\
\hline Ashoor et al ${ }^{15}$ & Targeted MPS & 397 & 297 (297) & $\begin{array}{l}\text { T21: } 50(50) \\
\text { T18: } 50(49)\end{array}$ & $\begin{array}{l}\text { T21: } 100 \text { (94.2-100) } \\
\text { T18: } 98 \text { (90.1-99.9) }\end{array}$ & $\begin{array}{l}\text { T21: } 100(99-100) \\
\text { T18: } 100(99-100)\end{array}$ \\
\hline
\end{tabular}

failure rate. These reports differ from many of the others in that they take other risk factors into account to give a risk of an individual fetus being affected. In so doing, they may well improve accuracy. Although the data reported here pertain to high-risk pregnancies, they are clearly aiming to deliver their test to the low-risk population as a highly accurate screening test for Down syndrome (DS) and other aneuploidies, as evidenced by the recent press release in which they launch a multicenter study of 25,000 pregnancies with the objective of comparing FORTE with current combined screening for DS. ${ }^{30}$

\section{Screening or diagnosis?}

That brings to the fore the issue of to whom and how these tests should be offered. Should it be to all women in early pregnancy as DS screening, or should it be used as an alternative to inva- sive diagnostic testing in those women identified as being at high risk following current screening-ie, as a sequential test? ? $^{31}$ Many factors will influence the answer to these questions: not just accuracy, but turnaround time, scalability, and cost. The latter will no doubt feature prominently in these times of economic hardship. But do we need to offer these new tests to all women, and should we do so anyway?

In the United Kingdom, many other parts of Europe, and the United States, government policy is that all women should be offered DS screening and/or diagnosis. ${ }^{32,33}$ Increasingly, DS screening is delivered by the first-trimester combined test, which is predicated on a combination of fetal ultrasound (to confirm gestation, the number of fetuses present and to assess the nuchal translucency measurement), and the levels of maternal serum biomarkers (pregnancy-associated plasma pro- 
TABLE 2

Projected numbers undergoing noninvasive prenatal diagnosis

\begin{tabular}{|c|c|c|c|c|c|c|c|c|c|c|}
\hline \multicolumn{3}{|l|}{ Screening } & \multicolumn{6}{|l|}{ NIPD } & \multicolumn{2}{|l|}{ CVS } \\
\hline Cut-off (1 in) & $\mathrm{DR}_{\mathrm{S}}$ & $\mathrm{FPR}_{\mathbf{S}}$ & NIPD & $\mathrm{DR}_{\mathrm{N}}$ & $\mathrm{FPR}_{\mathrm{N}}$ & $\mathrm{TP}_{\mathrm{N}}$ & $\mathrm{FP}_{\mathrm{N}}$ & $\mathrm{FN}_{\mathbf{S}+\mathbf{N}}$ & CVS & Miscarriages \\
\hline 150 & $85.0 \%$ & $2.5 \%$ & 13,646 & $99.0 \%$ & $1.0 \%$ & 1169 & 136 & 220 & 1305 & 13 \\
\hline 500 & $94.0 \%$ & $7 \%$ & 37,704 & $99.0 \%$ & $1.0 \%$ & 1293 & 377 & 96 & 1670 & 17 \\
\hline 1000 & $96.0 \%$ & $12 \%$ & 60,668 & $99.0 \%$ & $1.0 \%$ & 1320 & 607 & 69 & 1927 & 19 \\
\hline 2000 & $98.0 \%$ & $19 \%$ & 94,103 & $99.0 \%$ & $1.0 \%$ & 1348 & 941 & 41 & 2289 & 23 \\
\hline 5000 & $99.0 \%$ & $31 \%$ & 155,944 & $99.0 \%$ & $1.0 \%$ & 1361 & 1559 & 28 & 2921 & 29 \\
\hline 10,000 & $99.5 \%$ & $43 \%$ & 215,785 & $99.0 \%$ & $1.0 \%$ & 1368 & 2158 & 21 & 3526 & 35 \\
\hline
\end{tabular}

Figures calculated for hypothetical population of 500,000 women. With Down syndrome prevalence at screening of 1 in 360 number of affected fetuses is 1389 . Using invasive prenatal diagnosis rather than NIPD with screening cut-off of 1 in 150, 13,646 women would undergo CVS, detecting 1181 Down syndrome prevalence cases with estimated 136 miscarriages.

CVS , chorionic villus sampling; $D R_{N}$, detection rate with NIPD; $D R_{S}$, detection rate with screening; $F N_{S+N}$, combined false-negative results with screening and NIPD = number of Down syndrome prevalence cases $-\mathrm{TP}_{\mathrm{N}} ; F P_{N}$, false-positive results with NIPD; $F P R_{N}$, false-positive rate with NIPD; $F P R_{S}$, false-positive rate with screening; $N I P D$, noninvasive prenatal diagnosis; $T P_{N}$, true positives with NIPD.

Chitty. Noninvasive prenatal testing for aneuploidy. Am J Obstet Gynecol 2012.

tein A and human chorionic gonadotrophin), as it offers improved detection rates with fewer false-positive results than second-trimester serum screening. ${ }^{34}$ Those women with a given risk, in the United Kingdom it is $\geq 1: 150$, are then offered invasive tests for definitive diagnosis. There is also increasing evidence that the combined test screens for other complications of pregnancy including preeclampsia, ${ }^{35,36}$ intrauterine growth restriction, ${ }^{37,38}$ cardiac anomalies, ${ }^{39,40}$ and other anomalies and genetic syndromes. ${ }^{41-43}$ Furthermore, ultrasound will be required in the delivery of any test based on cffDNA, be it screening or diagnostic, as it will be necessary to confirm the gestational age and number of fetuses present to perform the test and interpret results. Given these observations, in countries such as the United Kingdom with well-established national screening programs, we must question whether any new test for DS should replace current screening tests. The alternative would be to use NIPD in conjunction with current screening, either to replace invasive testing or as a form of contingent screening, or in addition to the current screening tests. Given the economic constraints we face worldwide, the latter approach seems unlikely, but to abandon nuchal translucency, pregnancy-associated plasma protein A, and human chorionic gonadotrophin measurement and their potential benefits if programs are already well established also seems foolhardy.

\section{Economic considerations}

The relative cost of NIPD and invasive prenatal diagnosis (IPD) is likely to be an important factor in deciding how we implement NIPD, especially in cash-constrained publicly funded health care systems. The total cost of including NIPD in the DS diagnostic pathway depends on the cost of NIPD testing, numbers undergoing NIPD (a function of the propensity to offer diagnostic tests), and the accuracy of NIPD (because this may affect the use of confirmatory IPD testing). The cost of NIPD testing is likely to vary by country, and will probably decrease over time. The number undergoing NIPD will also vary by country, depending on screening policy and practice, but the accuracy of NIPD should be the same across countries, and will probably increase over time.

We chose to look at the costs of introducing NIPD in the United Kingdom as it is a publicly funded health care system with a well-defined care pathway where all pregnant women are offered screening for DS. The modeling is based on United Kingdom costs and estimated prevalence of DS in our population. We calculated the impact of introducing NIPD into the DS diagnostic pathway assuming that all high-risk women identified by screening would undergo NIPD, and that those with a positive NIPD would undergo confirmatory IPD. For the purposes of this commentary we have modeled costs based on a first-trimester screening program and used costs associated with chorionic villus sampling (CVS). Where possible we have used published cost data ${ }^{44}$ or data obtained from local hospitals. ${ }^{7}$ As mentioned above, these costs will change with time, and between countries. We assume DS prevalence at time of screening of 1 in $360,{ }^{45}$ so that in a hypothetical cohort of 500,000 pregnant women 1389 will have an affected fetus. Using a screening cut-off of 1 in 150 (the current United Kingdom standard) 13,646 women would undergo NIPD (Table 2). For the purposes of this discussion we have used a detection rate for NIPD of $99 \%$ and a false-positive rate of $1 \%$. This is based on the data from the large studies recently reported. ${ }^{8,9,28}$ Using these figures, 1305 of these women would subsequently undergo CVS, with 13 miscarriages, and 1169 DS cases detected. If

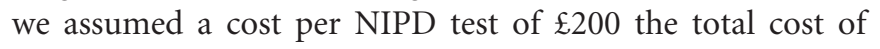
screening and diagnosis would be $£ 29.7$ million (Table 3 ).

Using IPD rather than NIPD with the same screening cutoff, 13,646 women would undergo CVS with an estimated 136 miscarriages and 1181 cases detected. The projected total cost

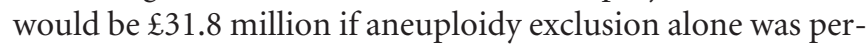
formed. Hence, with a cost per test of $£ 200$, a detection rate of $99 \%$, and a false-positive rate of $1 \%$, given the errors inherent in these estimates, the cost of NIPD and IPD are similar, but 
TABLE 3

Projected costs of noninvasive prenatal diagnosis

\begin{tabular}{|c|c|c|c|c|c|c|c|c|}
\hline $\begin{array}{l}\text { Screening cut-off } \\
\text { (1 in) }\end{array}$ & $\begin{array}{l}\text { Cost of screening } \\
\text { (£) }\end{array}$ & $\begin{array}{l}\text { Cost of CVS } \\
(\mathfrak{f})\end{array}$ & \multicolumn{2}{|c|}{ Cost/NIPD test $=£ 500$} & \multicolumn{2}{|c|}{ Cost/NIPD test $=£ 200$} & \multicolumn{2}{|c|}{ Cost/NIPD test $=£ 50$} \\
\hline 500 & $26,500,000$ & 644,443 & $18,852,083$ & $45,996,526$ & $7,540,833$ & $34,685,276$ & $1,885,208$ & $29,029,651$ \\
\hline 1000 & $26,500,000$ & 743,699 & $30,334,028$ & $57,577,726$ & $12,133,611$ & $39,377,310$ & $3,033,403$ & $30,277,101$ \\
\hline 5000 & $26,500,000$ & $1,127,388$ & $77,972,222$ & $105,599,610$ & $31,188,889$ & $58,816,277$ & $7,797,222$ & $35,424,610$ \\
\hline 10,000 & $26,500,000$ & $1,361,025$ & $107,892,361$ & $135,753,386$ & $43,156,944$ & $71,017,970$ & $10,789,236$ & $38,650,261$ \\
\hline \multicolumn{9}{|c|}{$\begin{array}{l}\text { Figures calculated for hypothetical population of } 500,000 \text { women, based on calculations in Table 2. Cost of screening }=£ 53 .{ }^{43} \text { Cost of CVS }=£ 386 .{ }^{7} \text { Cost of NIPD varied in table. We assume all } \\
\text { women with positive NIPD result would undergo CVS. Total cost }=\text { cost screening }+ \text { cost CVS }+ \text { cost NIPD. Using invasive prenatal diagnosis rather than NIPD with screening cut-off of } 1 \text { in } 150 \text {, } \\
\text { projected total cost would be } £ 26,500,000+£ 5,267,292=£ 31,767,292 \text {. } \\
\text { CVS, chorionic villus sampling; NIPD, noninvasive prenatal diagnosis. }\end{array}$} \\
\hline
\end{tabular}

with NIPD there will be fewer procedural-related losses of normal pregnancies and 12 fewer DS cases detected. If the cost per NIPD cost was higher or lower than $£ 200$ then this would affect the total cost (Table 3 ).

If the screening cut-off increased so that more women were offered NIPD, more DS cases would be detected but costs would increase. For example, using a screening cut-off of 1 in 2000 the screening detection rate would increase to $98 \%$, around 94,000 women would undergo NIPD, and 1348 DS cases would be detected. The total cost would be $£ 46.2$ million if the cost per NIPD test were $£ 200$. If the cost per NIPD test was $£ 50$ then the total cost would be similar to the total cost of IPD based on a screening cut-off of 1 in 150, with 167 more DS cases detected and fewer miscarriages.

If we abandoned the current DS screening programs and offered NIPD to all women, then at a cost of $£ 50$, NIPD would be as cheap as or cheaper than the contingent screening described above, since the cost of DS screening would be avoided, although an ultrasound scan would still be required to date the pregnancy. NIPD instead of screening would detect a high proportion of cases of trisomy 21 (99\%, or 1375 cases). However, with a false-positive rate of $1 \%$, around 6300 confirmatory CVS would be required, half the number required using IPD with a screening cut-off of 1 in 150.

Hence, depending on NIPD accuracy, trade-offs between uptake/screening cut-off and cost per test are possible, such that NIPD compares favorably with IPD in terms of costs, cases detected, and numbers of miscarriages. If the data reported in the small series described in this journal are confirmed in largerscale studies, and sensitivity and specificity approach $100 \%$, then these estimates will change, as indeed will the cost implications if more women chose to accept screening and diagnosis with the widespread adoption of a safer diagnostic test.

At present, the debate over where these new tests fit in the antenatal care pathway is largely academic. Evaluation to date has only been performed in high-risk populations and the small false-positive rate reported in the recent validation studies of NIPD for DS means that confirmation by invasive testing is required. As such the NIPD test can only be regarded as an "advanced screening test." ${ }^{12}$ Also of concern is the possibility of false-negative results. Data from current studies suggest false-negative rates are low; however, these studies have relatively small numbers of cases and have been conducted in the high-risk populations using samples from women who are at increased risk following DS screening. Much larger studies are required to accurately estimate the test specificity and it may be that implementation with close monitoring of pregnancy outcomes will be required to obtain true estimates of accuracy. In addition, it is not yet clear what the gestational limits of the test will be and this is a key factor in guiding where NIPD sits in the antenatal care pathway, although the data presented here by Ashoor et $\mathrm{al}^{15}$ focus on the first trimester.

Although holding off on widespread implementation until accuracy is nearly perfect may be the ideal held by health professionals, it may not in fact reflect women's values and needs. Health providers may hold different values from patients with respect to test attributes for DS screening. ${ }^{46}$ It would seem that opinions on NIPD also vary. Preliminary analysis of data collected in a discrete choice study comparing opinions of obstetricians and midwives with those of pregnant women in the United Kingdom clearly shows that, although both groups value safety and accuracy, women are prepared to accept reduced accuracy for greater safety, unlike the professionals who rate accuracy highest. Similarly in a US study of pregnant women's opinions and interest in NIPD for DS the majority of women $(75 \%)$ rated safety the most important factor of NIPD followed by accuracy (13\%) or early results $(7 \%) .{ }^{47}$

\section{The extent of diagnosis}

Implementation clearly has the potential to decrease the rate of invasive testing, but the focus so far has predominantly been on 
NIPD for trisomy 21, although the data presented in the papers reported here include targets for trisomy 18 , and others have explored the detection of the other major trisomies (Table 1). First-trimester screening algorithms increasingly include detection of trisomies 13 and $18,{ }^{48-50}$ and if full karyotyping is performed rather than rapid aneuploidy exclusion using fluorescence in situ hybridization or real-time-polymerase chain reaction, other chromosomal rearrangements with a high risk of adverse outcome are also detected in current service delivery models that include full karyotyping. Furthermore, the advent of detailed molecular karyotyping using multiplex ligation-dependent probe amplification or microarrays offers the potential for the prenatal detection of microdeletion syndromes and other pathogenic copy number variants conferring a high risk of adverse outcome. ${ }^{51,52}$ Our calculations have explored the costs and outcomes associated with NIPD following DS screening. If NIPD were to be implemented with the resultant decrease in invasive tests, there is some evidence that it would detect more DS cases and result in fewer miscarriages, but it would also detect fewer nontrisomy 21 chromosomal abnormalities. Although it seems likely that NIPD will be refined to include detection of the other major trisomies in the near future, techniques for the identification of other pathogenic rearrangements may take longer to develop. Prenatal diagnosis programs may need to include the option of invasive testing in those pregnancies where NIPD is normal but the fetus has an increased nuchal translucency or other structural abnormality, as it is well recognized that this is the group most likely to have other chromosomal rearrangements. ${ }^{53,54}$ The impact on costs in this setting will depend on the relative costs of NIPD, DS screening, and number of invasive tests performed.

\section{Counseling and ethical issues}

Exploration of the ethical and psychosocial issues associated with implementing NIPD has highlighted several concerns, including the potential to undermine informed consent, increased societal pressure to test and terminate affected pregnancies, and equity of access. ${ }^{55-57}$ The small number of studies evaluating stakeholder perception of the potential for NIPD for DS suggest a positive response to NIPD overall, but there is some unease about the potential negatives. ${ }^{46,58-61}$ One of the most debated issues regarding NIPD has been how best to ensure informed consent as there is concern that women may not give NIPD sufficient consideration because it will require "just a blood test." ${ }^{15-57}$ This is an ongoing problem for DS testing in general, as evidence from research on women's decision making for DS screening indicate that women do not always make informed decisions when taking up DS screening, ${ }^{62}$ or indeed are not fully aware of what screening tests they have had. ${ }^{63}$ Further concerns relate to the potential for increased societal pressure for testing and termination as tests become safer and easier to access; ${ }^{59-61}$ this includes pressure from commercial and insurance sectors that might perceive economic benefits in decreasing the prevalence of disorders. ${ }^{64}$
How NIPD is introduced in the screening and diagnostic pathway also has the potential to impact on informed consent. One of the key reasons women decline prenatal screening and diagnosis for DS is the risk of miscarriage. ${ }^{65}$ Currently the 2-step process of screening and diagnosis and the risk of miscarriage associated with diagnostic tests are thought to be psychological barriers to diagnostic testing that prompt women to think carefully about their options, and health professionals to provide information aimed at facilitating informed choice. If the miscarriage risk is removed, women may feel less justified in the decision not to have a test $;{ }^{66}$ they may give less thought to these tests and health professionals may give less information and be less concerned about obtaining informed consent. ${ }^{67}$ However, incorporation of NIPD into the screening pathway in conjunction with current screening as described above would preserve the 2-step process and at least offer the opportunity to focus on the possible outcomes that might arise albeit from a blood test rather than an invasive one.

Consequently, a major factor for the successful introduction of NIPD into routine antenatal care will be the development of approaches to counseling and strategies for information provision that will facilitate informed decision making. Key to this will be provision of education strategies to allow health professionals to become confident and capable of offering information and nondirective counseling about the test. A recent survey of obstetric health professionals from the United States found they were not secure in their current knowledge of NIPD. ${ }^{61}$ Moreover, in the United Kingdom it seems that health professionals consider NIPD to be more like current DS screening than invasive diagnostic testing in terms of the need for written consent and performing the test on the same day it is offered. ${ }^{67}$

\section{Commercial considerations}

So far as we are aware at the moment, NIPD for aneuploidy is only being offered through commercial providers. Access to the tests and costs are unclear, but seem to require referral via a physician who will be responsible for discussing results with women. One issue that could impede progress and the freedom to operate regards intellectual property rights. The prenatal diagnosis market is highly lucrative, therefore, understandably, commercial providers see NIPD as a major opportunity and are keen to capture the market. Although one company claims to hold all intellectual property rights for this testing, there are now several lawsuits in progress; undoubtedly, the patent landscape is complex and we can anticipate protracted suits and countersuits as the technology continues to develop and be implemented. From the patient's perspective, it is critical that access to testing is not restricted or curtailed as a result of patent enforcement. Further, hopefully commercial companies do not restrict access by pricing NIPD out of the market for widespread use, which might be a particular problem in publicly funded systems with fixed budgets.

These tests also lend themselves to direct-to-consumer marketing. Although this does not appear to be happening at the moment, at least for aneuploidy testing, it can cause difficulties 
as it may fall outside standard regulation practices making it difficult to ensure test accuracy, reliability, informed consent, or access. ${ }^{55,68}$ Notably, research into public attitudes identified concerns that people having NIPD outside a clinical setting would not receive sufficient support and counseling ${ }^{60}$ and a survey of health professionals in the United States found they did not support direct-to-consumer testing. ${ }^{61}$

\section{Conclusions}

The papers published here are no doubt only the first of many that will be seen this year describing potential approaches for delivery of NIPD. However, there is a long way to go yet before we see widespread implementation of NIPD for aneuploidy, but if we consider the pace of developments over the last couple of years, this may occur faster than anticipated. These new approaches must be evaluated in the appropriate populations, but in parallel we must develop health professional and patient education regarding limitations of the tests and the implications of results. High-quality pretest counseling to enable informed parental choice has always been a prerequisite of antenatal screening. Removal of the barriers caused by risk of miscarriage makes counseling an even more important feature of any service offering NIPD. Health services need to respond rapidly to developments to avoid patchy access via the commercial sector resulting in inequality of access for many women. The ultimate aim must be for platforms that are robust, lend themselves to high throughput with rapid turnaround times, and are cost-efficient. Whether this will be a sequencing platform, digital polymerase chain reaction, or another approach remains to be seen. Whatever platform is used, if this technology is to be applied to all women seeking antenatal care then the next steps are to establish large prospective studies of low-risk populations where all aspects are considered, including test performance, turnaround times, counseling requirements, and economic aspects. Finally, it is to be hoped that the issues around intellectual property rights are resolved promptly and do not impede implementation of technology that will clearly benefit families by delivering a test to those requesting screening that avoids the loss of normal pregnancies.

These developments in the field of NIPD are exciting and promise positive changes for prenatal care. With the knowledge that the introduction of NIPD into clinical practice for fetal sex determination has already reduced the need for invasive testing for women at risk of sex-linked conditions, we hope that this success will extend to other indications for NIPD, including DS, in the near future.

\section{REFERENCES}

1. Bianchi DW. From Michael to microarrays: 30 years of studying fetal cells and nucleic acids in maternal blood. Prenat Diagn 2010;30:622-3. 2. Lo YMD, Corbetta N, Chamberlain PF, et al. Presence of fetal DNA in maternal plasma and serum. Lancet 1997;350:485-7.

3. Clausen FB, Christiansen M, Steffensen R, et al. Report of the first nationally implemented clinical routine screening for fetal RHD in D- pregnant women to ascertain the requirement for antenatal $\mathrm{RhD}$ prophylaxis. Transfusion 2011 Oct 13 [epub ahead of print].

4. Bustamante-Aragones A, Rodriguez de Alba M, Gonzalez-Gonzalez C, et al. Fetal sex determination in maternal blood from the seventh week of gestation and its role in diagnosing hemophilia in the fetuses of female carriers. Haemophilia 2008;14:593-8.

5. Scheffer PG, van der Schoot CE, Page-Christiaens GC, et al. Reliability of fetal sex determination using maternal plasma. Obstet Gynecol 2010;115:117-26.

6. Hill M, Finning K, Martin P, et al. Non-invasive prenatal determination of fetal sex: translating research into clinical practice. Clin Genet 2011;80:68-75.

7. Hill M, Taffinder S, Chitty LS, Morris S. Incremental cost of non-invasive prenatal diagnosis versus invasive prenatal diagnosis of fetal sex in England. Prenat Diagn 2011;31:267-73.

8. Chiu RW, Akolekar R, Zheng YW, et al. Non-invasive prenatal assessment of trisomy 21 by multiplexed maternal plasma DNA sequencing: large scale validity study. BMJ 2011;342:c7401.

9. Palomaki GE, Kloza EM, Lambert-Messerlian GM, et al. DNA sequencing of maternal plasma to detect Down syndrome: an international clinical validation study. Genet Med 2011;13:913-20.

10. Devaney SA, Palomaki GE, Scott JA, Bianchi DW. Noninvasive fetal sex determination using cell-free fetal DNA: a systematic review and meta-analysis. JAMA 2011;306:627-36.

11. Verweij EJ, van den Oever JM, de Boer MA, Boon EM, Oepkes D. Diagnostic accuracy of noninvasive detection of fetal trisomy 21 in maternal blood: a systematic review. Fetal Diagn Ther 2011 Nov 17 [epub ahead of print].

12. Benn PA, Borrell A, Cuckle H, et al. Prenatal detection of Down syndrome using massively parallel sequencing (MPS): a rapid response position statement from a committee on behalf of the Board of the International Society for Prenatal Diagnosis, 24 October 2011. Prenat Diagn 2012;32:1-2.

13. Sparks AB, Wang ET, Struble $C A$, et al. Selective analysis of cell-free DNA in maternal blood for evaluation of fetal trisomy. Prenat Diagn 2012;32:3-9.

14. Sparks AB, Struble CA, Wang ET, Song K, Oliphant A. Noninvasive prenatal detection and selective analysis of cell-free DNA obtained from maternal blood: evaluation for trisomy 21 and trisomy 18. Am J Obstet Gynecol 2012;206:319.e1-9.

15. Ashoor G, Syngelaki A, Wagner M, Birdir C, Nicolaides KH. Chromosome selective sequencing of maternal plasma cell-free DNA for firsttrimester detection of trisomy 21 and trisomy 18. Am J Obstet Gynecol 2012;206:322.e1-5.

16. Lo YM, Tsui NB, Chiu RW, et al. Plasma placental RNA allelic ratio permits noninvasive prenatal chromosomal aneuploidy detection. Nat Med 2007;13:218-23.

17. Tsui NB, Akolekar R, Chiu RW, et al. Synergy of total PLAC4 RNA concentration and measurement of the RNA single-nucleotide polymorphism allelic ratio for the noninvasive prenatal detection of trisomy 21. Clin Chem 2010;56:73-81

18. Fan HC, Blumenfeld YJ, Chitkara U, Hudgins L, Quake SR. Noninvasive diagnosis of fetal aneuploidy by shotgun sequencing DNA from maternal blood. Proc Natl Acad Sci U S A 2008;105:16266-71.

19. Fan HC, Quake SR. Sensitivity of noninvasive prenatal detection of fetal aneuploidy from maternal plasma using shotgun sequencing is limited only by counting statistics. PLoS One 2010;5:e10439.

20. Chiu RW, Chan KC, Gao Y, et al. Noninvasive prenatal diagnosis of fetal chromosomal aneuploidy by massively parallel genomic sequencing of DNA in maternal plasma. Proc Natl Acad Sci U S A 2008;105:20458-63.

21. Ghanta $S$, Mitchell ME, Ames $M$, et al. Non-invasive prenatal detection of trisomy 21 using tandem single nucleotide polymorphisms. PLoS One 2010;5:e13184.

22. Tong YK, Jin S, Chiu RW, et al. Noninvasive prenatal detection of trisomy 21 by an epigenetic-genetic chromosome-dosage approach. Clin Chem 2010;56:90-8.

23. Papageorgiou EA, Karagrigoriou A, Tsaliki E, Velissariou V, Carter NP, Patsalis PC. Fetal-specific DNA methylation ratio permits noninvasive prenatal diagnosis of trisomy 21. Nat Med 2011;17:510-3.

24. Deng $\mathrm{YH}$, Yin $\mathrm{AH}, \mathrm{He} \mathrm{Q}$, et al. Non-invasive prenatal diagnosis of trisomy 21 by reverse transcriptase multiplex ligation-dependent probe amplification. Clin Chem Lab Med 2011;49:641-6.

25. Chiu RW, Sun $H$, Akolekar R, et al. Maternal plasma DNA analysis with massively parallel sequencing by ligation for noninvasive prenatal diagnosis of trisomy 21. Clin Chem 2010;56:459-63. 
26. Sehnert AJ, Rhees B, Comstock D, et al. Optimal detection of fetal chromosomal abnormalities by massively parallel DNA sequencing: of cell-free fetal DNA from maternal blood. Clin Chem 2011;57:1042-9.

27. Chen EZ, Chiu RW, Sun $H$, et al. Noninvasive prenatal diagnosis of fetal trisomy 18 and trisomy 13 by maternal plasma DNA sequencing. PLoS One 2011;6:e21791.

28. Ehrich M, Deciu C, Zwiefelhofer T, et al. Noninvasive detection of fetal trisomy 21 by sequencing of DNA in maternal blood: a study in a clinical setting. Am J Obstet Gynecol 2011;204:205.e1-11.

29. Lau TK, Chen F, Pan X, et al. Noninvasive prenatal diagnosis of common fetal chromosomal aneuploidies by maternal plasma DNA sequencing. J Matern Fetal Neonatal Med 2012 Feb 24 [epub ahead of print].

30. GenomeWeb. Aria kicks off clinical trial for non-invasive Down syndrome test. New York, NY: GenomeWeb LLC; Jan. 12, 2012. Available at: http://www.genomeweb.com/mdx/aria-kicks-clinical-trial-non-invasivedown-syndrome-test. Accessed Jan. 21, 2012.

31. Wright D, Bradbury I, Benn P, Cuckle H, Ritchie K. Contingent screening for Down syndrome is an efficient alternative to non-disclosure sequential screening. Prenat Diagn 2004;24:762-6.

32. American College of Obstetricians and Gynecologists. ACOG Committee on Practice Bulletins. ACOG practice bulletin: screening for fetal chromosome abnormalities. Obstet Gynecol 2007;109:217-26.

33. United Kingdom National Screening Committee. Antenatal screeningworking standards for Down's syndrome screening 2007. Available at: http:// fetalanomaly.screening.nhs.uk/standardsandpolicies. Accessed Jan. 30, 2012. 34. Nicolaides KH. Screening for fetal aneuploidies at 11 to 13 weeks. Prenat Diagn 2011;31:7-15.

35. Akolekar R, Syngelaki A, Sarquis R, Zvanca M, Nicolaides KH. Prediction of early, intermediate and late pre-eclampsia from maternal factors, biophysical and biochemical markers at 11-13 weeks. Prenat Diagn 2011;31:66-74.

36. Kuc S, Wortelboer EJ, van Rijn BB, Franx A, Visser GH, Scielen PC. Evaluation of 7 serum biomarkers and uterine artery Doppler ultrasound for first-trimester prediction of pre-eclampsia: a systematic review. Obstet Gynecol Surv 2011;66:225-39.

37. Karagiannis G, Akolekar R, Sarquis R, Wright D, Nicolaides KH. Prediction of small-for-gestation neonates from biophysical and biochemical markers at 11-13 weeks. Fetal Diagn Ther 2011;29:148-54.

38. Zhong Y, Tuuli M, Odibo AO. First-trimester assessment of placenta function and the prediction of pre-eclampsia and intrauterine growth restriction. Prenat Diagn 2010;30:293-308.

39. Clur SA, Van Brussel PM, Mathijssen IB, Pajkrt E, Ottenkamp J, Bilardo CM. Audit of 10 years of referrals for fetal echocardiography. Prenat Diagn 2011;31:1134-40.

40. Jouannic JM, Thieulin AC, Bonnet D, et al. Measurement of nuchal translucency for prenatal screening of congenital heart defects: a population-based evaluation. Prenat Diagn 2011;31:1264-9.

41. Souka AP, Von Kaisenberg CS, Hyett JA, Sonbek JD, Nicolaides KH. Increased nuchal translucency with normal karyotype. Am J Obstet Gynecol 2005;192:1005-21.

42. Syngelaki A, Chelemen T, Dagklis T, Allan L, Nicolaides KH. Prediction of early, intermediate and late pre-eclampsia from maternal factors, biophysical and biochemical markers at 11-13 weeks. Prenat Diagn 2011;31:66-74.

43. Alamillo CM, Fiddler M, Pergament E. Increased nuchal translucency in the presence of normal chromosomes: what's next? Curr Opin Obstet Gynecol 2012 Jan 24 [epub ahead of print].

44. Ritchie K, Bradbury I, Slattery J, Wright D, labal K, Penney G. Economic modelling of antenatal screening and ultrasound scanning programs for identification of fetal abnormalities. BJOG 2005;112:866-74. 45. Snijders RJ, Sundberg K, Holzgreve W, Henry G, Nicolaides KH. Maternal age- and gestation-specific risk for trisomy 21. Ultrasound Obstet Gynecol 1999;13:167-70.

46. Bishop AJ, Marteau TM, Armstrong D. Women and health care professionals' preferences for Down's syndrome screening tests: a conjoint analysis study. BJOG 2004;111:775-9.
47. Tischler R, Hudgins L, Blumenfeld YJ, Greely HT, Ormond KE. Noninvasive prenatal diagnosis: pregnant women's interest and expected uptake. Prenat Diagn 2011;31:1292-9.

48. Huttly WJ, Wald NJ. An audit of the detection of trisomy 18 in prenatal screening for Down syndrome using the Combined test. Prenat Diagn 2011;31:1317.

49. Sørensen S, Momsen G, Sundberg K, Friis-Hansen L, Jørgensen FS. First-trimester risk calculation for trisomy 13, 18, and 21: comparison of the screening efficiency between 2 locally developed programs and commercial software. Clin Chem 2011;57:1023-31.

50. Fetal Anomaly Screening Programme 2011. Available at: http:// fetalanomaly.screening.nhs. uk/T13and18consultation. Accessed Jan. 29, 2012.

51. Chitty LS, Kistler J, Akolekar R, Liddle S, Nicolaides K, Levett L. Multiplex ligation-dependent probe amplification (MLPA): a reliable alternative for fetal chromosome analysis? J Matern Fetal Neonatal Med 2011 Dec 6 [epub ahead of print].

52. Gruchy N, Decamp M, Richard N, et al. Array CGH analysis in highrisk pregnancies: comparing DNA from cultured cells and cell-free fetal DNA. Prenat Diagn 2011 Oct 24 [epub ahead of print].

53. Chitty LS, Kagan KO, Molina FS, Waters JJ, Nicolaides KH. Fetal nuchal translucency scan and early prenatal diagnosis of chromosomal abnormalities by rapid aneuploidy screening: observational study. BMJ 2006;332:452-5.

54. Kagan KO, Chitty LS, Cicero S, Eleftheriades M, Nicolaides KH. UItrasound findings before amniocentesis in selecting the method of analyzing the sample. Prenat Diagn 2007;27:34-9.

55. Wright CF. Cell-free fetal nucleic acids for non-invasive prenatal diagnosis. Report of the United Kingdom expert working group. PHG Foundation. Available at: http://wwwphgfoundationorg/reports/4985. Accessed Jan. 29, 2012.

56. de Jong A, Dondorp WJ, de Die-Smulders CE, Frints SG, de Wert GM. Non-invasive prenatal testing: ethical issues explored. Eur J Hum Genet 2010;18:272-7.

57. Deans Z, Newson AJ. Should non-invasiveness change informed consent procedures for prenatal diagnosis? Health Care Anal 2011;19:122-32.

58. Zamerowski ST, Lumley MA, Arreola RA, et al. Favorable attitudes toward testing for chromosomal abnormalities via analysis of fetal cells in maternal blood. Genet Med 2001;3:301-9.

59. Kooij L, Tymstra $T$, Berg $P$, et al. The attitude of women toward current and future possibilities of diagnostic testing in maternal blood using fetal DNA. Prenat Diagn 2009;29:164-8.

60. Kelly SE, Farrimond HR. Non-invasive prenatal genetic testing: a study of public attitudes. Public Health Genomics 2012;15:73-81.

61. Sayres LC, Allyse M, Norton ME, Cho MK. Cell-free fetal DNA testing: a pilot study of obstetric healthcare provider attitudes toward clinical implementation. Prenat Diagn 2011;31:1070-6.

62. van den Berg M, Timmermans DR, Ten Kate LP, van Vugt JM, van der Wal G. Are pregnant women making informed choices about prenatal screening? Genet Med 2005;7:332-8.

63. Seror V, Ville Y. Prenatal screening for Down syndrome: women's involvement in decision-making and their attitudes to screening. Prenat Diagn 2009;29:120-8.

64. Benn PA, Chapman AR. Practical and ethical considerations of noninvasive prenatal diagnosis. JAMA 2009;301:2154-6.

65. Kobelka C, Mattman A, Langlois S. An evaluation of the decisionmaking process regarding amniocentesis following a screen-positive maternal serum screen result. Prenat Diagn 2009;29:514-9.

66. Newson AJ. Ethical aspects arising from non-invasive fetal diagnosis. Semin Fetal Neonatal Med 2008;13:103-8.

67. van den Heuvel A, Chitty L, Dormandy E, et al. Will the introduction of non-invasive prenatal diagnostic testing erode informed choices? An experimental study of health care professionals. Patient Educ Couns 2010;78:24-8.

68. Hall A, Bostanci A, Wright CF. Non-invasive prenatal diagnosis using cell-free fetal DNA technology: applications and implications. Public Health Genomics 2010;13:246-55. 